\title{
Deserticulture Contributes to Targeted Poverty Alleviation Part I: An Advance Planting Test in Mu Us Sandy Land
}

\author{
Guangjun $\mathrm{Fu}^{1}$, Ningning Zhang ${ }^{2}$, Yan $\mathrm{Wen}^{3} \&$ Jiakun $\mathrm{Yan}^{2}$ \\ ${ }^{1}$ Desert control research institute of Shaanxi province, Yulin, Shaanxi, China \\ ${ }^{2}$ College of life science, Yulin University, Yulin, Shaanxi, China \\ ${ }^{3}$ Sand control station of Yuyang district, Yulin, Shaanxi, China \\ Correspondence: Jiakun Yan, College of life science, Yulin University, Yulin, Shaanxi, China. E-mail: \\ himingse@163.com
}

Received: October 8, 2018

Accepted: October 25, $2018 \quad$ Online Published: October 29, 2018

doi:10.5539/enrr.v8n4p12

URL: https://doi.org/10.5539/enrr.v8n4p12

\begin{abstract}
Nowadays, Chinese government is actively advancing the targeted poverty alleviation on a countrywide scale. It is difficult to conduct in some areas e.g. sandy land region and some arid and semi-arid region where the water is a shortage. In these areas, it is more important to solve ecological environment question than developing agriculture. So, to find some economic forest species that held certain ecological function of sand protection was in urgent need. Cerasus humilis, which has good health function and excellent in cold-resistance and drought-resistance, was introduced to Mu Us Sandy land. In this study, we found that this kind plant could well adapt to the sandy climate and bears fruit. In the future, the targeted poverty alleviation in the rural areas of northern Shaanxi will be based on planting Cerasus humilis gradually.
\end{abstract}

Keywords: targeted poverty alleviation, Mu Us Sandy land, Cerasus humilis

\section{Introduction}

The $\mathrm{Mu}$ Us Sandy land is one of the four major sandy lands in China, it has undergone oppressive desertification, mainly attributed to climate and anthropogenic activity such as over grazing, excessive farming intensity, and vegetation devastation by fuel wood acquisition. The desertification has not only led to an increase in bare soil and loss of soil resources (e.g. loss of nutrients and serious degradation of soil) but has also influenced the sustainable growth of the environment of China and the world. Therefore, to control land desertification and mitigate its negative impacts on grassland and farmland, the government of China has adopted many critical mechanical methods (such as the elimination of grazing via fencing, returning degraded farmland to forest and grassland, placing sand arresters and planting indigenous trees, shrubs and grasses) since the 1960s for the revegetation of decertified land in China such as the Mu Us Sandy land (Wei, 2001). During the past 50 years, the desertification management process on the Mu Us Sandy land has produced good ecological benefits and has significantly improved soil texture and physicochemical properties (Zhang, Wang, Yang, Yin, \& Ma, 2015). With these achievements in past decades, now we could think about how to use the sand land to help the local farmers to increase income and assist the national targeted poverty alleviation.

The "targeted poverty alleviation" was first proposed in Nov. 2013 by the president of the People's Republic of China. Unlike the previous "extensive poverty alleviation", the targeted poverty alleviation is "helping the real poverty, helping the poverty really" (Wang, Chen, \& Yan, 2016). It is the most effective measure to change the poverty. Shaanbei, as known as the northern Shaanxi province including Yan'an and Yulin, located in loess plateau and Mu Us Sandy land, belonged to the arid and semi-arid regions which also held cold winter. In the past, researchers aimed at increasing farmers' income and had done some beneficial exploration e.g. planting vineyards, while these plantations need too many human resources (Bingzhi; Li, Luan, Xueguiz, \& Puchao, 1999). Up to this, a new dominant species, Cerasus humilis, which has good health function and is resistant to cold and drought, was introduced and planted since Apr. 2016. Cerasus humilis fruits contain a variety of mineral elements beneficial to human health, especially higher calcium contents than the average. In recent years, there is an urgent need to enlarge cultivated area to meet the growing demand. If Cerasus humilis could 
grow well in Mu Us Sandy land, it will be good news for local resident and contribute to the national targeted poverty alleviation.

Here, in this study we focused on the ecological adaptability of the primal introduced species of Cerasus humilis. We also discussed the potential for Cerasus humilis to be planted in northern Shaanxi.

\section{Materials and Methods}

\subsection{Experimental Area and Cerasus humilis}

Experiment was conducted in loess and sand areas. Cerasus humilis. $c v$ Zhongtiao was selected in this experiment. The seed of Zhongtiao was planted in pot to germinate and seedlings of germination with large size in 2016 was transplanted to filed in April 2016 and April 2017. Another germination in 2017 with small size was transplanted in April 2017.

\subsection{Measure Method}

At the first two years, some general morphological indicators were invested used a vernier caliper and straightedge.

\subsection{Statistical analyses}

The statistical analyses were performed with SPSS version 13.0. Differences between the means were compared by means of the Least Significant Difference (LSD) test at $\mathrm{P}<0.05$. The figures were produced using SigmaPlot version 12.01 (Systat Software, Inc).

\section{Results and Discussion}

The survival rate of these seedlings was from $70.50 \%$ to $95.50 \%$ (Figure 1). The highest survival rate $95.50 \%$ was found in two-year-old seedlings, which might be due to the experience of a previous growth period. The lowest rate $70.5 \%$ was the seedlings planted in sand area, but it was no significant difference with these seedlings held the same age $(\mathrm{P}>0.05)$. We also found that the seedlings held two-year-old also had higher survival rate up to $90.50 \%$. This indicated that the seedlings with higher year old could been better for improving survival rate and in fact confirmed the Cerasus humilis could survive in the sand.

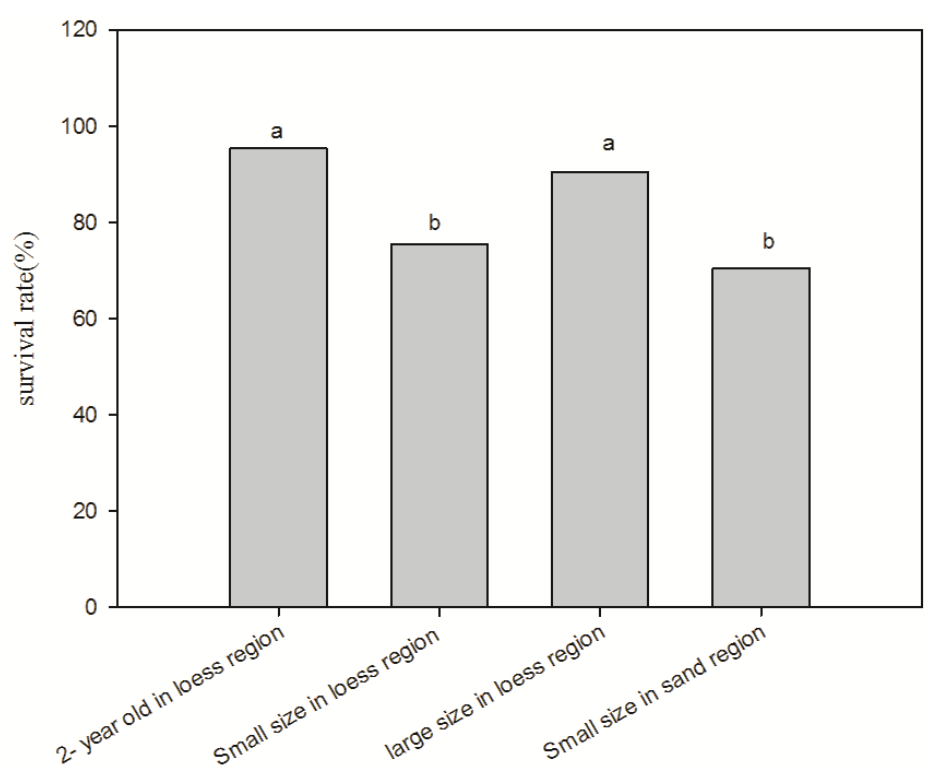

Figure 1. The survival rate of Cerasus humilis after planted for one- or two-years difference in size

The crown diameter was increased from 5 April to 12 May significantly ( $\mathrm{P}<0.05$, Figure $2 \mathrm{~B}$ ). According to Figure $3 \mathrm{~B}$, the seedlings planted in sandy land held the same growth rate of crown diameter to seedlings planted in loess region and the large size seedlings with two-years old held the highest growth rate of crown diameter and plant height, in which indexes two-years transplanted old seedling was the lowest. To ground diameter, we found that seedlings planted in sandy land could almost turned from the transplantation to growth fast (Figure 2A and Figure 3), and the plant height also had the same trend (Figure 2C), while the branching of seedlings in 
sandy land was less than that planted in loess region (Figure 2D). This showed that seedlings planted in sandy land seemed to recover from transplanting damage fast.
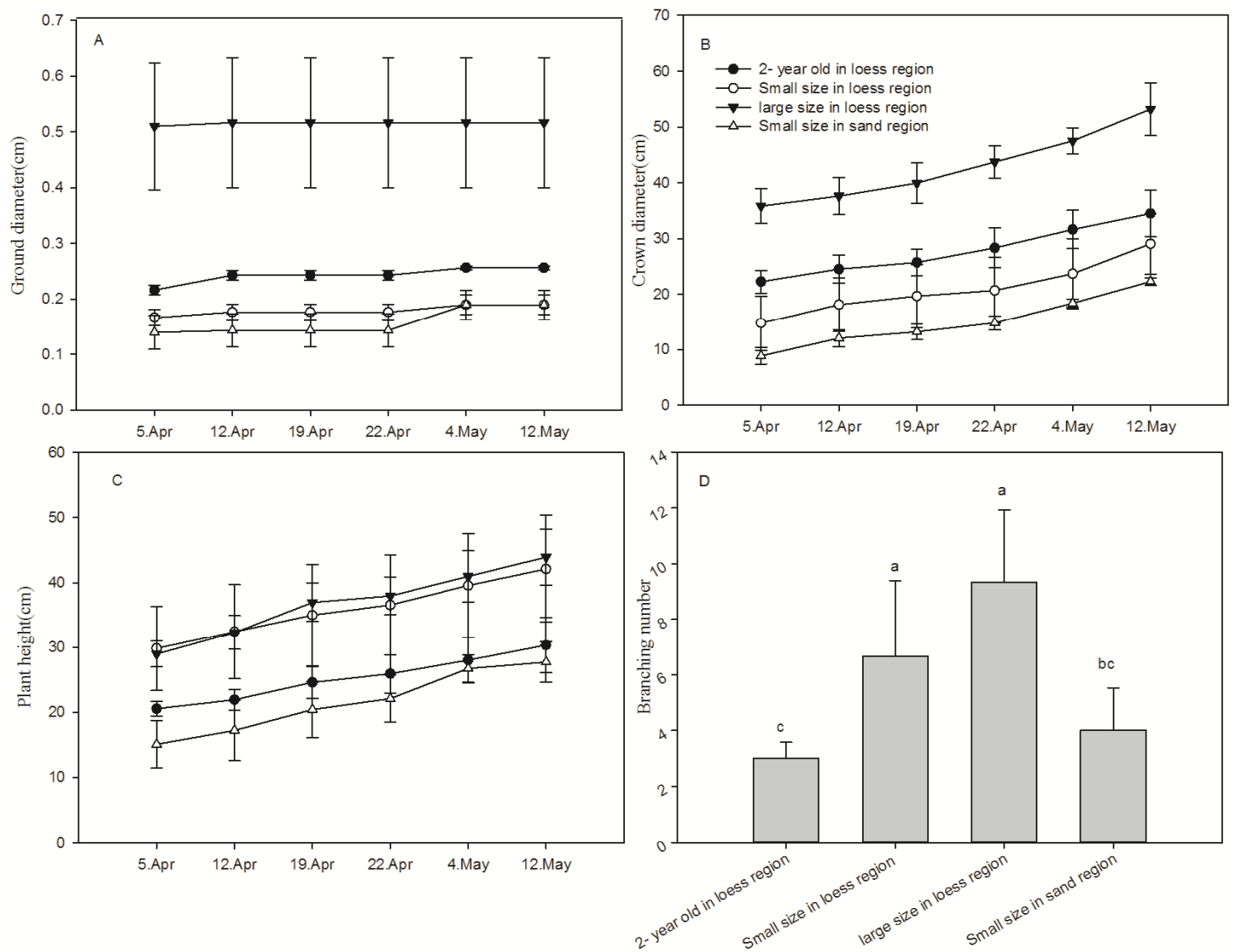

Figure 2. The morphological parameters of Cerasus humilis after planted for one- or two-years difference in size
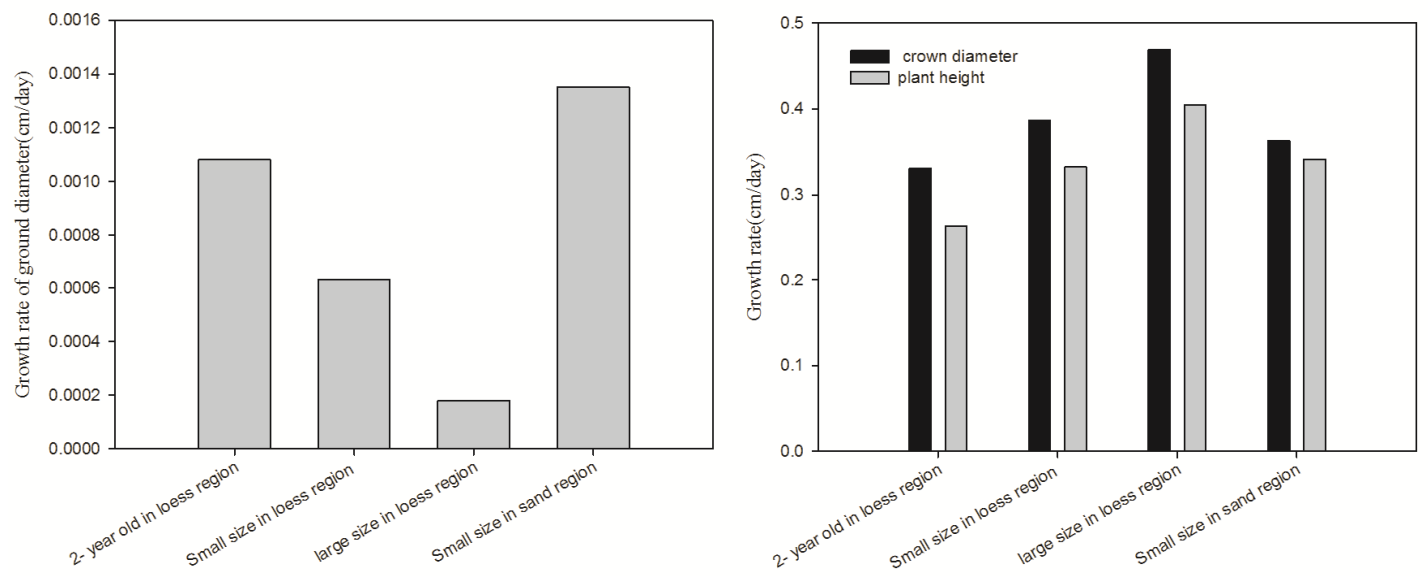

Figure 3. The growth rate of crown diameter, crown diameter and plant height

Due to age, small size Cerasus humilis seedlings could not bear ripe fruit (Figure 4), while the 2-year-old seedlings bear the similar size fruit.

In sandy land, there are many factors affecting the plant growth such as water shortage, high temperature in mid-soon, and cold winter (Hewitt, 1966; Baosheng; Li, Guangrong, Tonghu, \& Jiong, 1991). To the Mu Us Sandy land, the most important problems were the temperature and the seasonal rainfall, where the rain-fed was concentrated from July to September (Y. Song, Z. Liu, Zhou, Dang, \& S. Liu, 2006). Previous study had confirmed that the Cerasus humilis had stronger drought-resistance (X. S. Song et al., 2011). Here, we have 
confirmed that Cerasus humilis seedlings planted in sandy land also could bear the higher temperature of summer to bear fruit (Figure 4). These excellent tolerance to abiotic stress will benefit the large-scale cultivation.

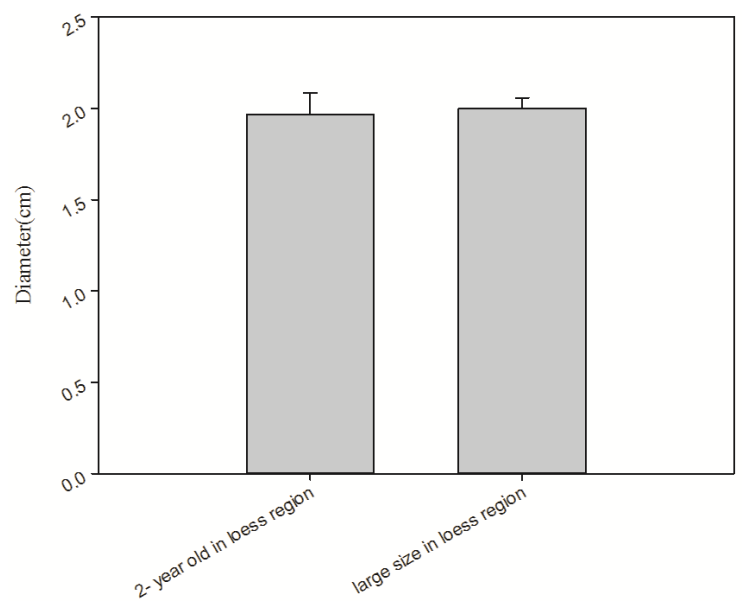

Figure 4. The size of Cerasus humilis fruit after planted for two years.

Nowadays, Chinese government is positive pushing the targeted poverty alleviation on a national scale. Cerasus humilis, known as a fruit of the same origin as medicine and food, was confirmed to be suitable for planting in the vast northern Shaanxi province in our study. In the future, the targeted poverty alleviation in the rural areas of northern Shaanxi based on planting Cerasus humilis will be presented gradually.

\section{Reference}

Hewitt, E. J. (1966). Sand and water culture methods used in the study of plant nutrition. Soil Science, 75(1), x + $241 ; 202-232$.

Li, B., Guangrong, T., Tonghu, D., \& Jiong, J. (1991). Some problems on wind-drift sand geomorphy in east taklimakan desert. Chinese Science Bulletin, 36(14), 1194-1194.

Li, B., Luan, D., Xueguiz, H., \& Puchao, H. (1999). Studies on cold resistance of grape varieties rootstocks and soil coverings in North Shaanxi. Acta Botanica Boreali-Occidentalia Sinica, 19(5), 139-143.

Song, X. S., Shang, Z. W., Yin, Z. P., Ren, J., Sun, M. C., \& Ma, X. L. (2011). Mechanism of xanthophyll-cycle-mediated photoprotection in Cerasus humilis seedlings under water stress and subsequent recovery. Photosynthetica, 49(4), 523-530. http://doi.org/10.1007/s11099-011-0065-4

Song, Y., Liu, Z., Zhou, Z., Dang, H., \& Liu, S. (2006). Temporal patterns of precipitation, evapotranspiration and the meaning to land use in Mu Us Sandland. Scientia Silvae Sinicae, 42(5), 6-10.

Wang, J., Chen, Y., \& Yan, M. (2016). Research on the Targeted Measures of Poverty Alleviation and Its Innovative Ways in China. Bulletin of Chinese Academy of Sciences, 3, 289-295.

Wei, W. (2001). Study on Process of Desertification in Mu Us Sandy Land for Last 50 Years, China. Journal of Desert Research, 21(2), 164-169.

Zhang, Y.-L., Wang, C.-Y., Yang, Y.-Q., Yin, F., \& Ma, B.-Z. (2015). Pressure nitric acid leaching of alkali-pretreated low-grade limonitic laterite. Rare Metals, 34(1), 64-70. http://doi.org/10.1007/s12598 $-014-0432-y$

\section{Copyrights}

Copyright for this article is retained by the author(s), with first publication rights granted to the journal.

This is an open-access article distributed under the terms and conditions of the Creative Commons Attribution license (http://creativecommons.org/licenses/by/4.0/). 